\title{
Microstructure, transformation characteristics and mechanical properties of thin TiNi films deposited from a planar magnetron source onto a cylindrical surface
}

\author{
V.V. Martynov, A.D. Johnson, V. Gupta and V. Galhotra \\ TiNi Alloy Company, 1621 Neptune Drive, San Leandro, CA 94577, U.S.A.
}

\begin{abstract}
Thin TiNi films (17 - 5 microns thick) deposited from a planar magnetron source onto a $6.35 \mathrm{~mm}$ diameter centerless ground rod (average surface roughness is about $1 \mathrm{micron}$ ) and onto a polished one (average surface roughness is about 0.02 micron) have been characterized. The film deposited onto a ground rod breaks very easily and can be removed from the substrate only in small pieces. It was found that the external surface of the film replicates all the imperfection of the original ground surface. The film has a plate-like grain structure with the "plates" stacked across the grinding marks aligned along them and perpendicular to the film surface. These "plates" have very poor cohesion between each other, and film easily brakes apart along the grinding marks. The film deposited onto a polished rod is strong enough to be pulled from the surface cut into samples $25 \times 1 \mathrm{~mm}$, and mechanically tested. The grain structure, external surface, roughness, and mechanical properties of the film were found to be dependent on the incident angle while the transformation characteristics of the film are almost independent of it.
\end{abstract}

\section{INTRODUCTION}

Sputter deposition has become a common process for thin film manufacturing from a large variety of target materials [1], and since 1990 it also has included the TiNi shape memory alloys [2,3]. The shape memory characteristics, mechanical properties, and transformation parameters of TiNi shape memory films have been shown to be strongly affected both by target composition and sputtering parameters. Among the other variables the sputtering parameters also include the substrate material and surface quality, the substrate temperature and incident angle of the deposition. Past investigations mainly focused on characterization of thin TiNi film deposited onto a polished planar surface, which is parallel to the surface of the target [4]. However, there is a need for TiNi films deposited and released from surfaces having different surface shape and surface quality. As TiNi alloy is a functional material, the film released from a substrate should not only have a certain shape and mechanical properties, but also have to posses the certain transformation parameters. The purpose of the present investigation is to characterize properties of TiNi shape memory films deposited from a planar magnetron source onto cylinders of a different surface roughness.

\section{EXPERIMENTAL TECHNIQUE}

A PE 4400 Production Sputtering System was used for DC magnetron sputter deposition from a $\sim 200$ $\mathrm{mm}$ diameter TiNi alloy (47wt.\%Ti- 53wt.\%Ni) target. The starting pressure in the chamber before opening of an argon flow was $1.0 \times 10^{-7}$ torr. During the deposition argon pressure was maintained at $\sim 2$ militorr, applied voltage $\sim 500 \mathrm{~V}$, current $\sim 4 \mathrm{~A}$, with the pallet to target distance $\sim 45 \mathrm{~mm}$. Films were sputtered for 30 min onto the surface of two $100 \mathrm{~mm}$ long $6.35 \mathrm{~mm}$ diameter high carbon steel rods placed side by side on the pallet under the center of the target. One of the rods was centerless ground and had pronounced grinding marks. The other one was mechanically polished using several diamond abrasive pastes from 3 down to 0.1 microns grade. The average surface roughness, as measured by the TENCOR Instruments Alpha-step profilometer, was $\sim 1$ micron for the ground rod and $\sim 0.02$ microns for the polished one. The same profilometer was also used for film thickness measurements.

As it was shown in earlier investigations in as-deposited state TiNi films are exhibiting an amorphous structure [5]. Therefore, deposited films were annealed at $\sim 500^{\circ} \mathrm{C}$ in a vacuum better than $5 \times 10^{-5}$ torr for 
crystallization purposes. Annealed films were separated from the substrates for the further analysis. The phase transformation intervals were determined using a direct current four-point probe resistivity method. Resistance versus temperature curves were automatically recorded while sample was uniformly heated and cooled in the temperature range from $-100^{\circ} \mathrm{C}$ to $150^{\circ} \mathrm{C}$ at the rates of approximately $10^{\circ} \mathrm{C}$ per minute. For characterization mechanical properties of the films the stress - strain curves were obtained using a custom made tensile device. The ISI SS60 scanning electron microscope was used for taking images of the fracture surface for films broken both while pulling from the substrate or during tension experiments.

\section{RESULTS AND DISCUSSION}

To release the deposited and annealed film from the polished rod, a rectangular area of the film approximately $7 \times 25 \mathrm{~mm}$ was scratched along the perimeter and gently pulled from the cylinder using the sharp tweezers and adhesive tape. Then the tape with attached film was adhered to a silicon substrate and cut by a diamond dicing wheel into samples using Tempress 602 dicing machine. From each film four samples $1 \times 25 \mathrm{~mm}$ were cut (referred to as \#1, \#2, \#3, and \#4) and used for resistivity measurements, tensile tests, and SEM examination. The total range of incidence angles (the angles between the cylinder radius and a perpendicular to the target surface) covered by the four samples was $\sim 80$ degrees starting from zero with $\sim 20$ degree increment per sample. Small pieces of the film broken in the process of separation it from the substrate were also used for SEM observations.

Film deposited onto the ground rod was not strong enough to be removed from the surface in pieces large enough to be used either for the resistivity measurements or mechanical testing. While pulling from the surface, the film easily tears apart along the grinding marks on the rod surface until it meets a major scratch along the rod when it brakes off. The pieces of the film (as large as $3 \times 4 \mathrm{~mm}$ ) pulled out of the rod surface were used for the SEM observation only.

\subsection{Film deposited onto the polished rod}

The thickness of the film deposited onto the polished rod was measured and found to vary from 17 microns on the top of the rod (the incidence angle was zero degrees) to 5 microns on its side (the incidence angle was 90 degrees) as it shown in Fig. 1. The appearance of the external surface of the film depends on the incidence angle. Only that part of it which corresponds to the incidence angles range of approximately $+/-20$ degrees appears bright and shiny. The more the incidence angle deviates from 20 degrees the more hazy (milky) the surface appears. The surface profile of the film measured by profilometer at different incidence angles reveals surface features that didn't exist on the polished surface. Both the average amplitude of these features and the average distance between them depends on the incidence angle. In the incidence angles range from 0 to 60 degrees the average amplitude of these features increases from $\sim 0.04$ to 0.07 microns, and the average distance between them in the same angle range changes from 5 to $\sim 1$ microns.

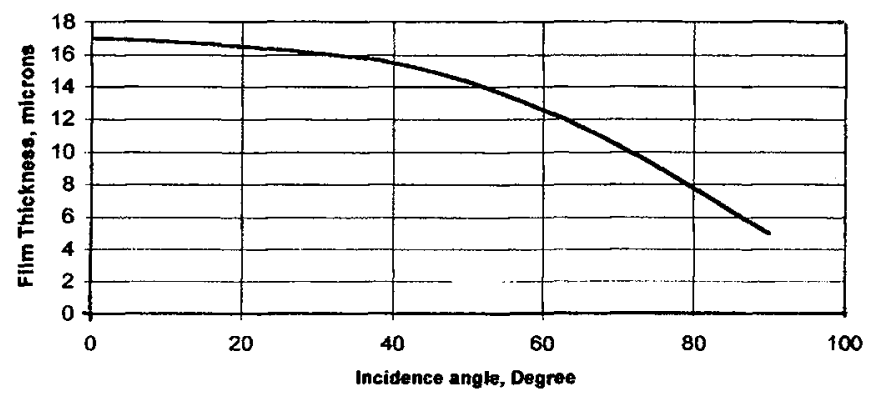

Figu re 1: Thickness variation for film deposited onto the polished rod. 


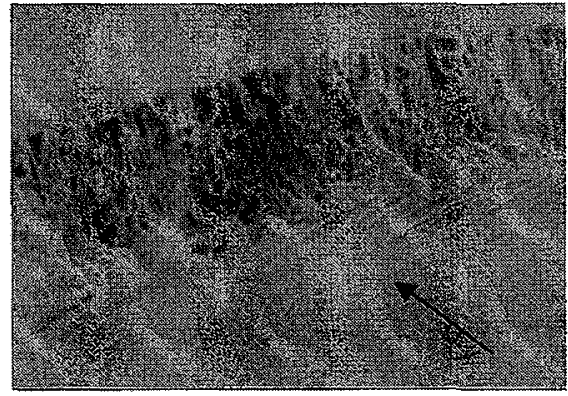

a

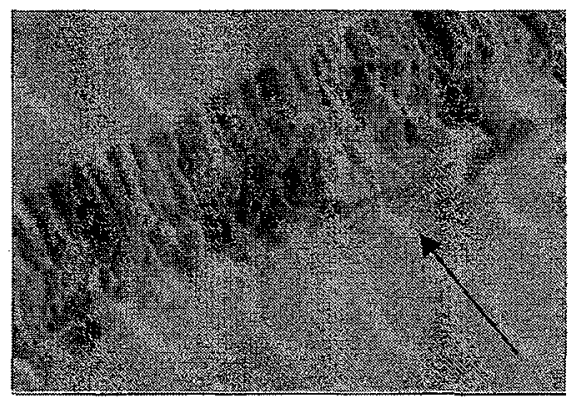

$c$

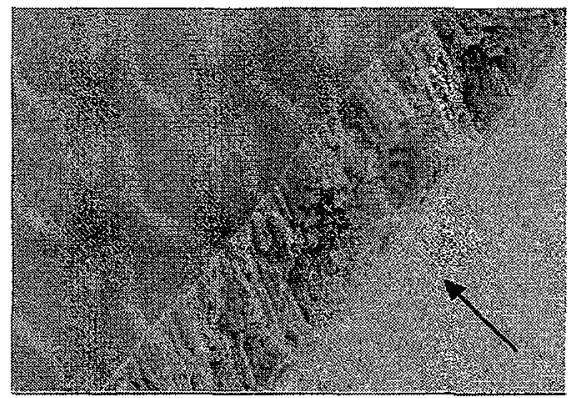

e

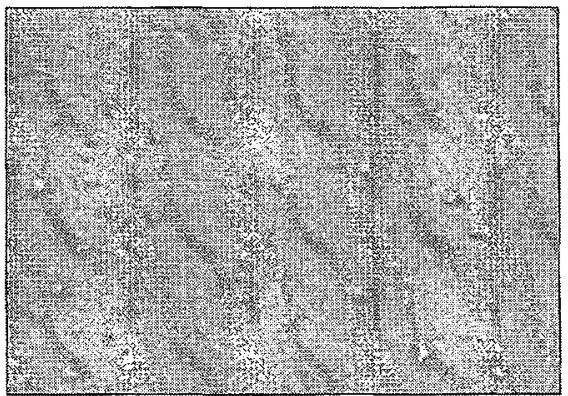

b

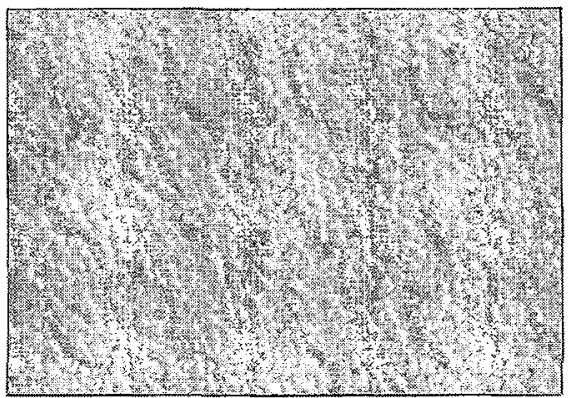

d

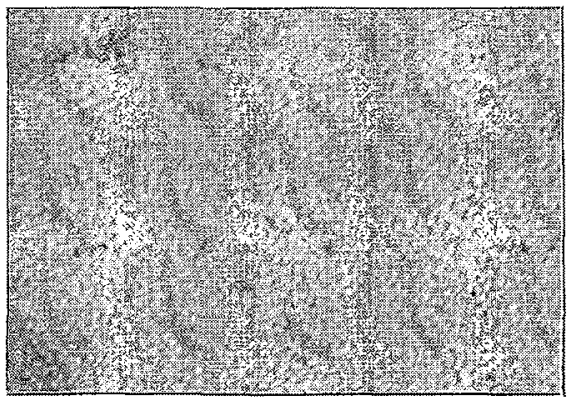

f

Figure 2: Film deposited onto the polished rod. The fracture $(a, c, e)$ and the external $(b, d, f)$ surfaces of the film for the incident angles: $\sim 0$ degree $(a, b), \sim 30$ degree $(c, d)$ and $\sim 60$ degree $(e, f)$. Arrow is pointing at the internal film surface.

Fig.2 shows the fracture surfaces and the external surface appearance of the film released from the polished rod. One can see that appearance of the external surface of the film at different deposition angles (Fig. $2 \mathrm{~b}, \mathrm{~d}, \mathrm{f}$ ) correlates with the profilometer measurements described above. The internal surface of the film away from the fracture replicates the rod surface while just near the fracture surface the deformation relief due to martensite formation can be seen.

As the incidence angle deviates from zero degree, the microstructure of the film tends to become more columnar with the columns normal to the film surface. In the part of the film deposited at a small incidence angle, the column-like grains occur only occasionally in the area close to the external surface (Fig. 2a). The column-like grains become longer and occur more often at the incidence angle of $\sim 30$ degree (Fig. 2c), and eventually, when the deposition angle is $\sim 60$ degree, they go almost through the 
whole cross section (Fig. 2e). The column-like grains have poor adherence to each other, resulting in easy initiation of cracks on the external film surface (Fig. 3) and overall low mechanical strength of the film.

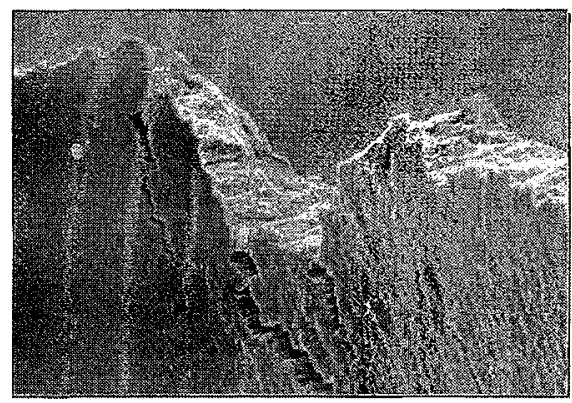

a

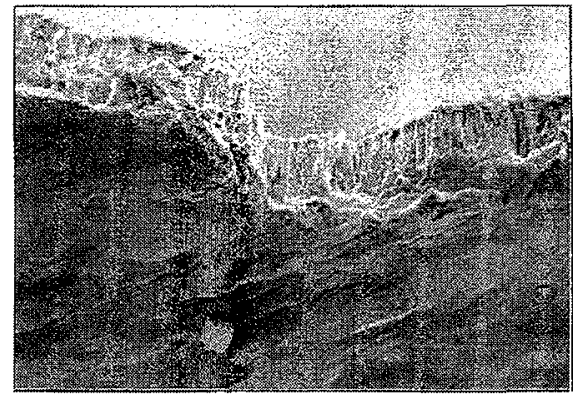

b

Figure 3: Film deposited onto the polished rod. Cracked (external - a) and plastically deformed (internal - b) sides of a broken film (incident angle $\sim 30$ degree).

As the result of this behaviour, out of four samples cut from the film corresponding to different deposition angles, only sample \#1 was strong enough to demonstrate closed superelasticity loop at $37 \mathrm{C}$ (Fig. 4.). Sample \#2 broke in the middle of the loading plateau. Samples \#3 and \#4 did not survive even the initial linear portion of the stress-strain curve.
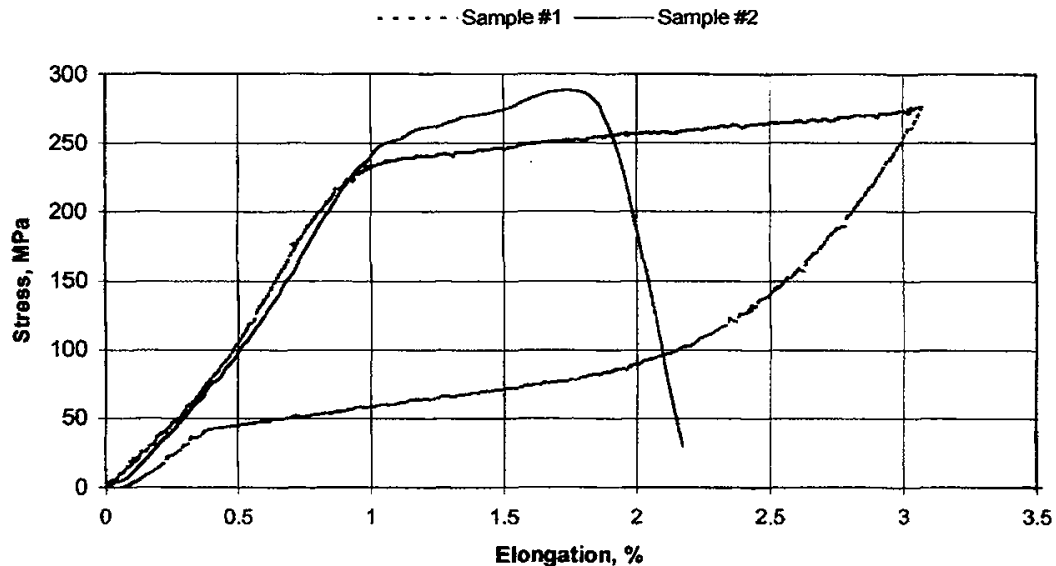

Figu re 4: Stress-strain curves at $37 \mathrm{C}$ for samples \#1 and \#2.

Although both the grain structure and mechanical properties of the film show strong dependence on the incidence angle, the transformation intervals are almost independent of it and reveal only relatively small shift towards the low temperatures. The difference in the martensitic transformation intervals for the sample \#1 and the sample \#4 was observed to be $\sim 10 \mathrm{C}$ (Fig. 5). 


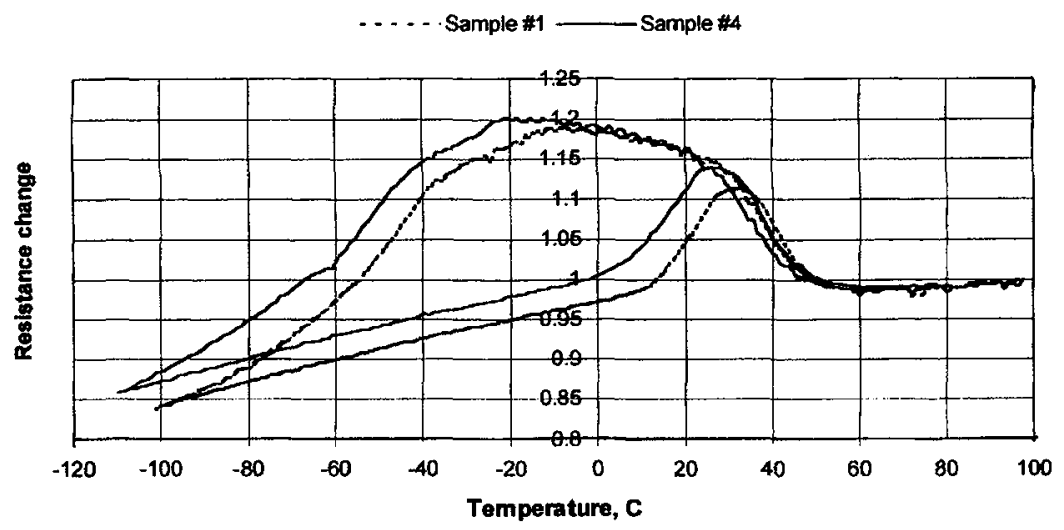

Figure. 5: Film deposited onto the polished rod. Transformation intervals for samples \#1 and \#4.

\subsection{Film deposited onto the ground rod}

The external surface of the film deposited onto the ground rod in all major features replicates the underlying ground surface (Fig. 8). Although not as evident as in the previous case, one can also notice the increased haziness of the surface while the incidence angle changes from zero to 90 degrees. Additional surface features appearing on the external film surface at large incidence angles and responsible for the haziness effect are distinctly seen on SEM images (Fig. 6). However, in surface profile measurements they are disguised among the major grinding marks, and these measurements don't reveal them.

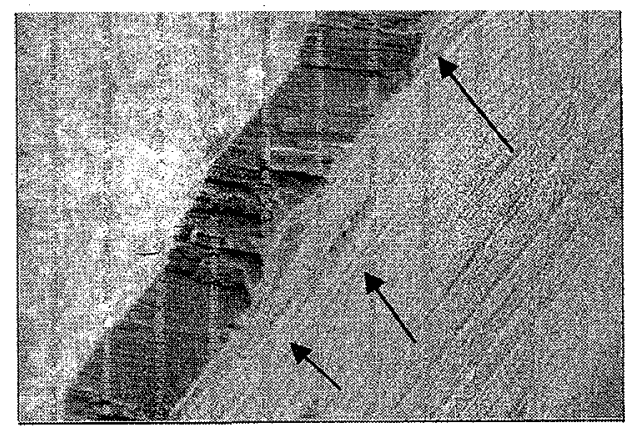

a

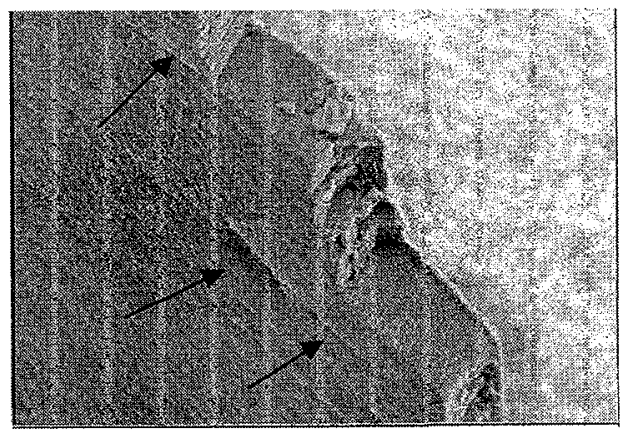

b

Figure 6: Film deposited onto the ground rod. Grinding marks on the internal (a) and external (b) surfaces of the film.

The uneven surface of the grinding marks on the rod surface gives rise to a very specific grain structure of the deposited film which can be described as plate-like. The "plates" are stacked across the grinding marks and aligned along them. The larger the incident angles the thinner the individual "plates" are (Fig. 7). This plate-like structure is responsible for the poor film strength in the direction across the "plates". Films brake easily along the grinding marks demonstrating poor cohesion between the "plates" (Fig. 6 and 7). 


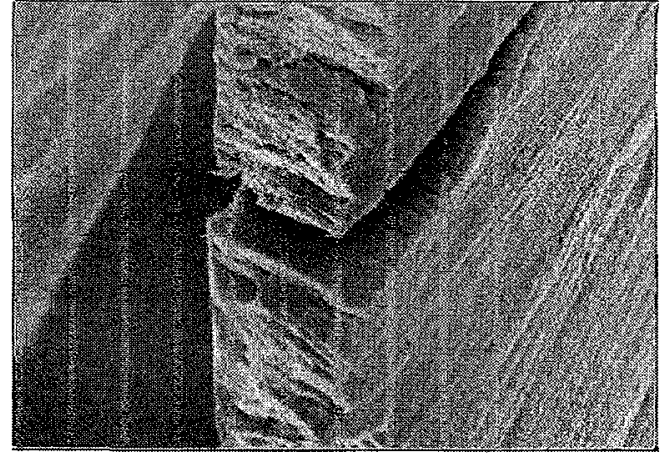

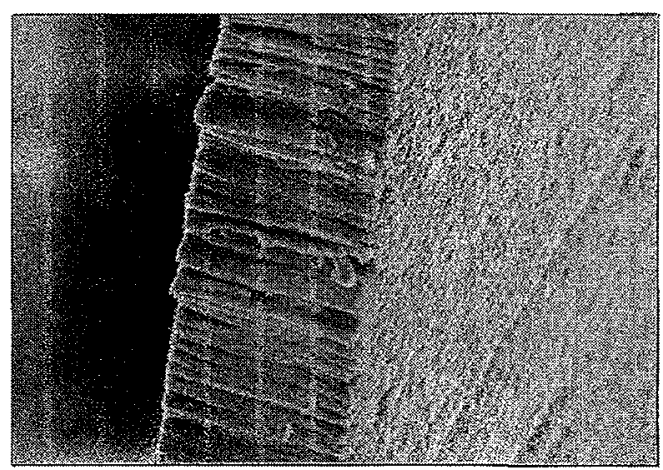

b

Figure 7: Film deposited onto the ground rod. Fracture surface of the film broken across the grinding marks: a - incident angle $\sim 10$ degree, $b-$ incident angle $\sim 60$ degree.

There are indirect evidences of the fact that at smaller incidence angles cohesion between the "plates" is stronger than at larger ones. However, overall poor mechanical properties of the film didn't allow quantitative measurements of the film strength.

\section{Conclusions}

- Mechanical properties of TiNi shape memory film deposited from a planar magnetron source onto a cylindrical surface were shown to be strongly dependent on the deposition angle and the substrate surface quality.

- With a polished substrate surface, the increase in the incidence angle tends to develop in the deposited film a column-like grain structure having the poor cohesion between the adjacent grains.

- The micron-scale surface defects of the substrate result in development of a specific grain structure in the associated film area, which is responsible for a low mechanical strength of the film.

\section{Acknowledgements}

The authors would like to gratefully acknowledge the financial support of Smart Therapeutic Inc. for this work.

\section{References}

1. L.I. Maissel and R. Gland (eds.), Handbook of Thin Film Technology, New York, McGraw Hill, (1970)

2. J.D. Busch, A.D. Johnson, C.H. Lee, and D.A. Stevenson, J. Appl. Phys. 12, 68, (1990), p. 6224.

3. J.D. Bush, A.D. Johnson, Proceedings of Micro Electro Mechanical Systems (MEMS-90), (1990), p. 40.

4. S. Miyazaki, A. Ishida, Materials Science and Engineering, A273-275 (1999), p. 106.

5. W.G. Moberly, J.D. Busch, A.D. Johnson, M.H Berkson., Phase transformation kinetics in thin films, Chen, M.O. Thompson, R.B. Schwarz, M. Libera (eds.), Pittsburgh, (1992), p. 85. 